\title{
HERBERT MARCUSE E A TEORIA CRÍTICA: PARA ALÉM DA PERSPECTIVA NORMATIVA DA ESCOLA DE FRANKFURT
}

\author{
Silvio Ricardo Gomes Carneiro ${ }^{1}$
}

\begin{abstract}
Resumo:
Nosso ensaio procura compreender o sentido atual da Teoria Crítica de Herbert Marcuse. De início, fazemos a contraposição de Marcuse à versão mais contemporânea da Teoria Crítica, representada pela perspectiva normativa de Jürgen Habermas e Axel Honneth. Notamos, em seguida, a insuficiência deste modelo crítico diante dos desafios contemporâneos, conforme a crítica de John Abromeit e Amy Allen. Ambos apresentam os limites da segunda geração para compreender o avanço do pensamento conservador. Recuperamos aqui as reflexões de Marcuse sobre os limites da democracia burguesa nos anos 1970. Este será o mote para pensarmos uma perspectiva de Teoria Crítica diversa da normatividade. A experiência crítica de Marcuse é marcada pelo contorno dos acontecimentos e dos corpos, o conteúdo material das questões morais - elementos centrais para o embate contra a cultura do medo que alimenta o autoritarismo nas vias democráticas.
\end{abstract}

Palavras-chave: Herbert Marcuse. Normatividade. Democracia. Teoria Crítica. Autoritarismo.

\section{HERBERT MARCUSE AND CRITICAL THEORY: BEYOND THE NORMATIVE PERSPECTIVE OF THE FRANKFURT SCHOOL}

\begin{abstract}
:
We intend to present some aspects of the Herbert Marcuse's Critical Theory in contemporary times. At first, we show the opposition between Marcuse and the last version of Critical Theory, developed by the normative perspective in Jürgen Habermas and Axel Honneth. Then, we show the insufficiencies of the normative perspective in front of the contemporary challenges, according to John Abromeit and Amy Allen. Both of them present some limits of the normative Critical Theory to understand the actual phenomena of conservative thinking. From this point, we need to propose a Critical Theory different from its Normative perspective. Marcuse's critic experience presents such differences: his criticism to bourgeoise democracy follow the dynamic of the events and the expressions of the body. Such elements are central to present the "material content of the moral issues", an important perspective to the conquest of the fear, the social affect that harbor the authoritarianism in democratic ways.
\end{abstract}

Keywords: Herbert Marcuse. Normativity. Democracy. Critical Theory. Authoritarianism.

\section{Introdução}

Qual mensagem na garrafa nos deixa um autor como Herbert Marcuse? Pensemos com essa questão, de início, a estranha compreensão sobre a atualidade de um autor marcado pelas experiências do século passado. Se observarmos os livros desse autor, podemos concluir que muitas das experiências derivam da realidade dos anos 1960 e 1970. A tecnologia

1 Silvio Ricardo Gomes Carneiro é professor do Centro de Ciências Naturais e Humanidades da Universidade Federal do ABC. Pesquisador do grupo NEXOS: Teoria Crítica e Pesquisa Interdisciplinar e da Rede Escola Pública e Universidade. Também é membro associado da International Herbert Marcuse Society. E-mail: silviocarneiro@gmail.com. 
utilizada na indústria daquele tempo, os modos de consumo de um Estado de Bem-Estar social, o clima de Guerra Fria: tudo parece imagens de uma fotografia já desbotada. No entanto, o impacto do pensamento de Marcuse parece ressoar em seu diálogo com movimentos sociais que explodem em nosso tempo junto a uma série de experiências e que ampliam nossa compreensão das lutas políticas. Nesse sentido, compreendemos aqui algo que a psicanálise concebe como "estranhamento": nas mensagens deixadas por Marcuse localizamos algo que nos é simultaneamente tão perto e tão longe.

Assim, o exercício pelo qual podemos introduzir uma reflexão sobre a mensagem marcuseana na garrafa atravessa a experiência de nossa reflexão para se questionar: afinal, o que faz da experiência marcuseana algo vivo para nosso tempo? Embora existam muitas lições do período, não seria o conteúdo nostálgico sobre os gloriosos anos 1960, da juventude rebelde em afinidade eletiva com a letra de Eros e civilização ou O homem unidimensional. Há algo mais potente nesse encontro que atravessa o conteúdo histórico e localizado na experiência daquele tempo a reforçar o eco do pensamento de Marcuse em nosso tempo como um alarme de incêndio. E isso não está no referencial do passado apenas, como se agora estivéssemos vivendo uma espécie de versão atualizada de um filme antigo: como se agora vivêssemos a repetição da Guerra Fria (sem uma União Soviética); como se nosso mundo do trabalho não estivesse há muito tempo já atravessado por racionalidades tecnológicas mais complexas do que a indústria e o Estado daqueles tempos; como se a ideologia neoliberal não se apropriasse de novos materiais sociais em conformidade com novas estruturas subjetivas; ou ainda, em contrapartida a todo esse cenário, como se as lutas antiglobalização e as formas de organização progressistas também não encontrassem novas formas de emancipação e solidariedade. Acreditamos que a leitura atualizada de Marcuse supere a nostalgia e avance junto a sua experiência militante em aliança com seus exercícios críticos. Talvez essa advertência inicial já nos adiante bastante uma melhor localização da atualidade de Marcuse no mapa contemporâneo.

Pois bem: qual filtro utilizaremos para fazer da mensagem na garrafa uma imagem em constelação com nosso tempo? Talvez, de início, a distância entre as experiências críticas de ontem e de hoje pode ser enfrentada menos pelos conteúdos denunciados ou anunciados na obra marcuseana do que pela forma aberta adotada pela atitude crítica de Marcuse. Claro, essa aposta não deslegitima os elementos que a experiência crítica marcuseana atravessou (muito do que criticava ainda marca presença em nosso tempo). Mas é possível

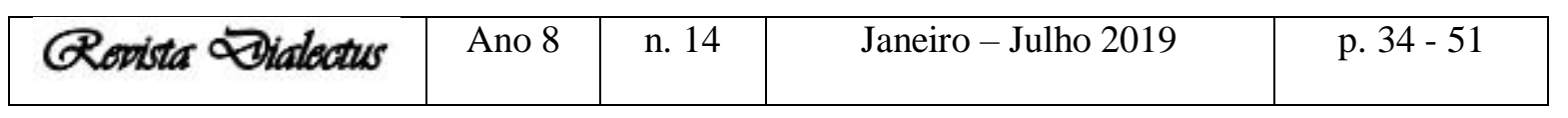


calibrar ainda melhor nosso foco ao retomar o ponto de partida de $O$ homem dimensional, como um exemplo interessante de um impulso recorrente da Teoria Crítica de nosso autor. Pois sua atualidade não está, de imediato, no diagnóstico mais realista do presente (tarefa da Teoria Tradicional) e sim, no modo como enfrenta os desafios de seu tempo. A obra de Marcuse é, pois, atual na sua atitude crítica. Não é por outra razão que $O$ homem unidimensional tem em sua introdução as inquietações sobre si mesmo: a "paralisia da crítica".

\section{Marcuse e o destino da crítica}

Apresentar-se assim não é oferecer o discurso pessimista como saída, incorporando a impotência intelectual diante do abismo do mundo. De outro modo, significa mobilizar todos os elementos, revisar os pressupostos da Teoria Crítica, repensar a filosofia social de modo contínuo e notar a dinâmica constante dos conceitos, as mediações ora abertas, ora impedidas, e mesmo as possibilidades de emancipação sem ilusões de fuga, mas junto à possibilidade histórica de sua obsolescência. Em um de seus primeiros textos para o Instituto de Pesquisas Sociais, Marcuse considera que a "teoria crítica, por fim, é crítica contra si mesma e contra seus próprios defensores sociais" (MARCUSE, 1997, p. 157). Com isso, não defende uma crítica abstrata a todos os princípios. De outro modo, nosso autor extrai as consequências do que Horkheimer já indicava em "Teoria Tradicional e Teoria Crítica", diferenciando estas duas teorias, em grande medida, pelo "comportamento crítico" [kritische Verhalten].

Neste ensaio, que em grande medida orienta as bases da Teoria Crítica da primeira geração de Frankfurt, Horkheimer marca a diferença da Teoria que concebe como "tradicional" (em grande medida vinculada às linhas cientificistas do positivismo) em defesa de sua teoria crítica. A teoria tradicional admite como existente sua "participação no processo renovador da vida da totalidade" atuando em uma sociedade que funciona. Assim, a posição do cientista tem em vista a meta da realização do estado racional com bases nas raízes da miséria presente. Algo que mobiliza sua defesa do progresso industrial e tecnológico contra as agruras da humanidade. Todavia, adverte Horkheimer, "o modo de ser dessa miséria não oferece a imagem de sua superação" (1983, p. 137). Isto é, o cientista da Teoria Tradicional deixa de lado os custos de seu progresso, não observa a miséria promovida contraditoriamente pelo seu desenvolvimento, de modo que "o mesmo sujeito que quer impor os fatos de uma realidade melhor pode também representa-la" e, nesse sentido, promove a miséria que sua teoria produz (HORKHEIMER,

\begin{tabular}{|c|c|c|c|c|} 
Gevista Dialectus & Ano 8 & n. 14 & Janeiro - Julho 2019 & p. $34-51$ \\
\hline
\end{tabular}


1983, p. 137). A Teoria Tradicional, pois, se efetiva à imagem e semelhança do status quo que a sustenta, mantendo o fundo de miséria que a produz.

Outra trilha é perseguida pela Teoria Crítica. Seu ponto de partida é a oposição da realidade dada, seu diagnóstico não é a reprodução da imagem social, sua miséria não é um desvio da racionalidade estabelecida. O "comportamento crítico" parte desse ponto: uma "contradição consciente" em que a imagem do progresso acompanha a história de dominação. É olhar, pois, o retrato social pelo seu "negativo", observando que as imagens estabelecidas se sustentam no espectro de tensões. Nesse esforço de superar as tensões sem encobri-las pelo horizonte do progresso, a miséria toma a forma de estruturante social. Ao mesmo tempo, o sujeito crítico se encontra imerso neste todo contraditório, cuja tensão entre a miséria e o progresso exige dele uma atitude crítica intrinsecamente ligada à responsabilidade de produzir um saber que pese a si mesmo como parte dessa produção social. O que sustenta essa perspectiva crítica, pois, é o "comportamento crítico" que configura um sujeito na negação de sua realidade e de si mesmo como parte desta realidade, um conceito de humanidade que contraria a si na medida mesma em que a experiência é atravessada por um mundo que não é dela. É uma realidade estruturada na divisão social em que a miséria estruturante é seu produto desumano. Nesta atitude, o pensamento crítico se efetiva no modo negativo da realidade: a partir da miséria, o teórico crítico encontra os rastros da emancipação e no progresso estabelecido os signos de uma vida precária.

É esta atitude crítica que acompanha Marcuse em seu capítulo introdutório de $O$ homem unidimensional: "A Paralisia da Crítica: sociedade sem oposição". Por esse subtítulo não devemos compreender o sinônimo de uma sociedade sem conflitos, ou mesmo, em linguagem marxista, a ausência da dominação própria a uma sociedade dividida hierarquicamente entre classes. Marcuse quer indicar um problema grave no coração da teoria crítica: uma sociedade sem oposição é a ilusão de uma sociedade estabelecida em uma aparente realidade sem contradições e, portanto, sem o dispositivo central do pensamento crítico: sem os elementos que propicia a negação do Establishment. Com isso, Marcuse quer refletir sobre o destino da Teoria Crítica em uma realidade pela qual os conflitos sociais (e suas categorias) foram absorvidos por uma dinâmica social que os integra como parte de seu progresso: sob a marca da racionalidade unidimensional tudo se submete ao desempenho e à eficiência de um único modelo social em que o jogo de classes se submete à operacionalidade integrada a uma única estrutura social. Conforme lembra Marcuse, antigas categorias que nos primeiros anos do

\begin{tabular}{|l|l|l|l|l|}
\hline Qevista Qialectus & Ano 8 & n. 14 & Janeiro - Julho 2019 & p. 34 - 51 \\
\hline
\end{tabular}


capitalismo seriam vistas como antagônicas (como família, sociedade versus Estado) passam a ser integrantes de um mesmo campo de relações em vista do progresso único do sistema. ${ }^{2}$ Eis o que Marcuse identifica como o caráter unidimensional que atravessa a sociedade e o pensamento: elemento que bloqueia o "comportamento crítico" alimentado, em grande medida pelo horizonte negativo que outrora orientava todo processo emancipatório.

Em um tal grau de integração, Marcuse questiona-se por sua própria experiência de modo a retirar a teoria crítica da paralisia. Tarefa que oferece enormes dificuldades. Não é simples, como sugere no Prefácio Político (1966) quando lembra que o potencial negativo das liberdades ainda não realizadas. Em uma sociedade unidimensional, com o grau tecnológico e as vias sociais abertas por este, não faz mais sentido falar sobre libertação aos homens livres da classe média branca, não faz mais sentido falar de repressão sexual quando homens e mulheres gozam de uma liberdade sexual jamais vista antes. A crítica à modernidade se paralisa em campos que lhes eram muito familiares. Aos poucos, Marcuse se aproxima do "inferno" que toda essa liberdade ilumina: o preço que todo esse progresso social cobra nos guetos, nos rincões dos continentes em uma nova ordem imperial. Decerto, é possível que haja tecnologia capaz de abastecer o mundo e mapear os bolsões de miséria. Mas a que preço?

Fazer-se esta pergunta não é um exercício de simples retórica: implica em mudanças nas categorias básicas da teoria crítica: implica uma nova ordem de juízo capaz de enfrentar a realidade objetiva e seu novo jogo unidimensional. Em breves termos, a introdução de $O$ homem unidimensional indica esta operação: recupera o sentido de crítica enquanto juízo de valores em dois níveis. Primeiramente, um juízo que pressupõe a priori a vida humana como um valor digno de ser vivido. Mas também, em segundo, um juízo que pressupõe que em uma dada sociedade, existem possibilidades específicas de melhoria da vida humana e modos e meios específicos para realizar estas possibilidades (MARCUSE, 1991, p. XLI). Em outras palavras, Marcuse procura recuperar a orientação crítica pela qual o juízo deve se fiar entre um a priori erótico que valoriza a vida humana na sociedade, mas também reconhece que, $a$ posteriori, o status quo não é uma realidade monolítica e cristalizada. Pelo contrário, está prenhe de possibilidades de mudança. A teoria crítica de Marcuse se desenvolve pois, entre a

2 Devemos lembrar aqui que, mesmo no jogo de forças da Guerra Fria, o jogo seria operado entre duas potências no interior de uma mesma finalidade em disputa. A corrida espacial e o projeto de Guerra nas Estrelas submetem ambos os modelos sociais ao mesmo poderio de destruição bélico e controle social. Marcuse reconhece este paralelo das potências em $O$ homem unidimensional, assim como já havia associada a submissão da experiência soviética ao capitalismo em Marxismo Soviético, em seu estágio estalinista.

\begin{tabular}{|c|c|c|c|c|}
\hline Gevista Dialectus & Ano 8 & n. 14 & Janeiro - Julho 2019 & p. $34-51$ \\
\hline
\end{tabular}


vida humana como valor universal a priori e as rupturas com o estado de dominação materialmente possibilitadas pelas próprias condições culturais, políticas e econômicas desenvolvidas historicamente. Todo o problema passa a operar, no entanto, quando a crítica perde o antigo solo negativo das oposições sociais. Na realidade unidimensional, pensamento e sociedade operam na dinâmica das oposições integradas, de modo que a demanda por liberdades pode ser a cifra que reforça o domínio social.

O impasse que Marcuse alcança em $O$ homem unidimensional é um capítulo à parte entre as gerações seguintes da Escola de Frankfurt, que buscam determinar o papel da crítica. Muitos deles, a partir da leitura de Habermas, compreendem todo o aparato do juízo crítico fundamentado no campo normativo. Axel Honneth compreende que "um problema central da Teoria Crítica da sociedade é a conexão entre a intenção teórico-normativa e a moralidade historicamente situada." (2007, p. 80). Assim, o juízo crítico de valor que Marcuse descreve em $O$ homem unidimensional representaria para Honneth um exemplo desse procedimento: a intenção teórico-normativa de um a priori erótico em conexão com as possibilidades efetivas de transformação social em um contexto histórico situado.

Seria o enquadramento normativo de Habermas e Honneth o mais correto para descrever a Teoria Crítica de Marcuse? Compreendamos melhor essa passagem para, em seguida, pensarmos um pouco a presença de Marcuse diante dos desafios da atualidade.

\section{O giro normativo}

Decerto, as últimas gerações da Escola de Frankfurt foram absorvidas pela perspectiva normativa de seus diagnósticos do presente. ${ }^{3}$ Sobre isso, Axel Honneth ressalta que a Teoria Crítica da Sociedade se vincula a um "tipo de pensamento social que partilha uma forma particular de crítica normativa" pela qual podemos nos informar sobre as "instâncias préteóricas [vorwissenschafltiche Instanz] em que sua própria perspectiva crítica está ancorada extra-teoricamente como um interesse empírico ou uma experiência moral" (HONNETH, 2007, p. 63-64). Em outras palavras, uma teoria crítica cujas bases se consolidam tanto no desenvolvimento da observação empírica das ciências sociais e psicológicas quanto na consolidação de critérios éticos que propiciem um julgamento sobre as injustiças sociais. Assim, na anterior diferença entre a Teoria Tradicional e a Teoria Crítica, a perspectiva

\footnotetext{
${ }^{3}$ Não apenas Habermas, mas podemos destacar também as pesquisas seguintes de Axel Honneth, Seyla Benhabib ou Rainer Forst.
}

\begin{tabular}{|c|c|c|c|c|}
\hline Gevista Dialectus & Ano 8 & n. 14 & Janeiro - Julho 2019 & p. $34-51$ \\
\hline
\end{tabular}


normativa desta possibilitaria considerar a subjetividade em sua relação social, de modo a refletir tanto as bases sociais e psicológicas que constituem as relações no mundo da vida, mas também conferir uma dimensão prática com a aplicação orientada para uma práxis futura. Enfim, o diagnóstico crítico destas últimas gerações lança a Teoria Crítica para uma ação orientada normativamente, reconhecendo os conflitos sociais em um horizonte regulamentado pela base empírica de um saber contemporâneo sobre a intersubjetividade e a expectativa ética da justiça moldada pelo reconhecimento.

Nesse sentido, podemos compreender quando Honneth compreende o projeto da teoria crítica na análise das expectativas normativas de sujeitos em relação, cujo desapontamento "se torna uma fonte constante de demandas morais que vão além das formas especificamente estabelecidas de dominação.” (HONNETH, 2007, p. 69) Muito embora esta descrição remeta aos procedimentos normativos de Habermas, identificamos também aqui o modo como Honneth apresenta sua gramática dos conflitos sociais. Em seu Disrespect: the normative foundations of Critical Theory, Honneth apresenta a oposição normativa do reconhecimento/desrespeito como o eixo de seu diagnóstico social. Ora, os conflitos sociais seriam efeitos do déficit de reconhecimento mediante os quais as demandas sociais passam a ser apresentadas. Com isso, Honneth procura trazer à luz os modelos políticos de conflitos que atravessam as lutas de classes e os movimentos por direitos civis. ${ }^{4}$ Por conseguinte, o esforço diagnóstico da teoria crítica segue a expectativa normativa em que "modelos institucionalizados de reconhecimento social geram demandas justificadas nos modos como os sujeitos se tratam.”(HONNETH, 2007, p. XIII). Apoiado em modelos antropológicos e psicológicos dos processos de socialização, Honneth apresenta não apenas os déficits de reconhecimento social, mas também propõe horizontes de reconhecimento que atravessam as dimensões dos afetos, dos direitos e mesmo do ethos social em que estão implicadas as relações intersubjetivas (HONNETH, 2003).

Com isso, Honneth indica um distanciamento das formulações que seriam próprias à primeira geração de Frankfurt. Segundo Honneth (e Habermas), seus antecessores apresentam uma "fraqueza", pois o programa da filosofia social propiciada por Horkheimer sofre de um "reducionismo funcional" nas "premissas histórico-filosóficas" profundamente enraizadas na tradição marxista de uma racionalidade instrumental que organiza a sociedade capitalista

4 Sobre essa retomada dos movimentos sociais na teoria crítica contemporânea, ver o debate entre Axel Honneth e Nancy Fraser em Redistribution or Recognition? A Political-Philosophical Exchange.

\begin{tabular}{|c|c|c|c|c|}
\hline Ronista Dialectus & Ano 8 & n. 14 & Janeiro - Julho 2019 & p. $34-51$ \\
\hline
\end{tabular}


(HONNETH in GIDDENS et al, 1999, p. 516-517). Isso implica compreender a vertente crítica da primeira geração em uma relação ainda fixada nos parâmetros de uma filosofia do sujeito, uma vez que na instrumentalização o que está em jogo é o domínio do sujeito sobre o objeto, o que também significa a reificação dos sujeitos sociais. Não há espaço, de início, a outros sistemas sociais presentes no mundo da vida, reduzindo a história da humanidade em um "desdobramento desenvolvimentista do procedimento societal da natureza" (HONNETH in GIDDENS et al, 1999, p. 517). No limite, conclui Habermas (mas também, Honneth), a teoria crítica da primeira geração reduz funcionalmente sua orientação normativa a uma "contradição performativa" (HABERMAS, 2000, p. 170). Todo o desdobramento de seus diagnósticos gira em torno do modelo histórico-filosófico da racionalidade instrumental e, por isso, resultam em um modelo crítico paralisado de Horkheimer, Adorno e mesmo Marcuse. Nas palavras de Honneth:

\begin{abstract}
Uma vez que nenhum outro tipo de ação social é concedido, ao lado do trabalho societário, Horkheimer [mas também os demais membros desta geração] só pode levar sistematicamente em conta as formas instrumentais de prática societária no nível da teoria da sociedade, perdendo assim de vista essa dimensão da prática diária na qual os sujeitos socializados geram e desenvolvem criativamente orientações de ações comuns de um modo comunicativo. (HONNETH in GIDDENS et al., 1999, p. 518, colchetes nossos).
\end{abstract}

Consideremos aqui não apenas a marca que Honneth procura assinalar entre as gerações, mas a atitude crítica que acompanha seu gesto. Decerto, o autor procura avançar sobre os impasses que um novo contexto histórico-social oferece à teoria crítica. O que Habermas procurou estabelecer é um horizonte normativo que leve em consideração a ordem de relações intersubjetivas que ocupam e dinamizam a esfera pública. Honneth acompanha em sua gramática dos conflitos sociais muitas das lições habermasianas baseadas no reconhecimento intersubjetivo mediado pela esfera comunicativa - passo que a geração de Horkheimer não deu (HONNETH in GIDDENS et al, 1999, p. 518). Detendo-se um pouco mais na gramática do reconhecimento, Honneth afirma

As condições de um processo para alcançar a compreensão livre da dominação não podem mais ser empregadas como um critério para o que tem sido observado como uma 'desordem' ou um desenvolvimento patológico da vida social; antes, o critério

\begin{tabular}{|c|c|c|c|c|}
\hline Gevista Qialectus & Ano 8 & n. 14 & Janeiro - Julho 2019 & p. 34 - 51 \\
\hline
\end{tabular}


agora se torna a condição intersubjetiva do desenvolvimento da identidade humana (2007, p. 74).

Seriam, pois, os processos de autorrealização dos indivíduos em seus processos de socialização um dos critérios pelos quais Honneth abrange sua formulação crítica. Daí a importância de um ethos social que reconheça a justiça na dinâmica pessoal e social, inclusive na esfera do trabalho, mas também em toda a ordem normativa que atravessa os movimentos sociais étnico-raciais, de gênero e demais direitos civis e culturais. Impulso crítico que se apresenta à contrapelo dos sentidos de injustiça presentes nas dimensões individuais dos afetos, mas também intersubjetivas do campo jurídico ou mesmo culturais que habitam os valores sociais.

Novamente, a teoria crítica passa por uma revisão de seus pressupostos, em vistas do diagnóstico de seu tempo. Em debate com Nancy Fraser, muito desse "giro normativo" é justificado por Honneth pelos desafios de uma nova série de movimentos sociais que clamam não apenas por uma justiça econômico-política distributiva, mas também pelo reconhecimento dos valores culturais. ${ }^{5}$ Conforme este autor, seria essa nova dimensão dos conflitos sociais que exigem da Teoria Crítica um reforço cada vez maior em seus fundamentos normativos. Afinal, “os esforços multifatoriais de uma luta por reconhecimento são aqueles que capacitarão a Teoria Crítica a justificar suas pretensões normativas" (HONNETH, 2007, p. 77). Esta abertura a uma normatividade orientada por múltiplos fatores é o que Honneth não consegue identificar na ordem filosófico-histórica que identifica na primeira geração de Frankfurt. Resta saber em que medida na "fraqueza" da primeira geração de Frankfurt reside de fato um déficit normativo para os desafios contemporâneos e o novo cenário que se apresenta em dias de populismos conservadores.

\section{Críticas à normatividade}

Em tempos mais recentes, a perspectiva normativa da Teoria Crítica vem sendo revisada ou mesmo criticada a partir de limites impostos pelos tempos contemporâneos. Destaco aqui a objeção apresentada por John Abromeit que, na ocasião da ascensão de Donald Trump à presidência dos EUA, questionou-se pelos limites da perspectiva normativa da Teoria Crítica no cenário neoliberal ou ultraliberal que então se anunciava. Em que medida, questiona

\footnotetext{
${ }^{5}$ Ver o debate em FRASER E HONNETH, Redistribution or Recognition? A Political-Philosophical Exchange.
}

\begin{tabular}{|c|c|c|c|c|}
\hline Gevista Dialectus & Ano 8 & n. 14 & Janeiro - Julho 2019 & p. $34-51$ \\
\hline
\end{tabular}


Abromeit, as perspectivas de Habermas e Honneth nos ajudam a compreender os retrocessos sociais destas formas neoliberais de 'modernização', tais como a Grande Recessão de 2008 e o ressurgimento do populismo de direita na Europa e nos EUA? Em outras palavras: baseada no horizonte normativo de expectativas previstas em um campo institucional das lutas por reconhecimento, seria a teoria crítica de base normativa ainda capaz de promover uma perspectiva que supere a dinâmica contemporânea do pensamento conservador?

Decerto, a desregulamentação institucional em defesa da livre iniciativa do mercado e da competição entre indivíduos parece não operar mais sob o crivo da legitimação normativa. Em contrapartida, Abromeit lembra que em grande medida, a perspectiva normativa que a defesa liberal do fortalecimento das instituições democráticas presente no projeto iluminista de Habermas, torna secundário o processo histórico de dominação reduzido ao diagnóstico de patologias. Em um processo de revisão dos fundamentos e contextualização histórica das diferentes gerações de Teoria Crítica, o artigo de Abromeit identifica as diferenças e sugere limites para o fundamento normativo. Diante das crises frequentes do capitalismo, do aumento massivo de desigualdades e da proliferação dos movimentos populistas de direita, a perspectiva de um projeto inacabado de modernidade que alimenta o campo normativo do diagnóstico habermasiano, faz Abromeit lançar suspeitas e recuperar, diante destes limites, elementos presentes na primeira geração (ABROMEIT, 2017, p. 4).

Ora, segundo Abromeit, ao instaurar o campo normativo no núcleo da Teoria Crítica, a perspectiva que Habermas formula acaba perdendo um eixo importante para a compreensão de tais crises: o risco do autoritarismo no interior da própria democracia. Decerto, é importante lembrar, tanto Habermas quanto a geração que o segue estão engajados no combate aos revisionismos históricos conservadores e procuram responder aos movimentos regressivos da contemporaneidade. O problema, pois, está em outro plano: seria a resposta mediada pelo campo normativo suficiente? O que Abromeit procura identificar como limite da perspectiva normativa é, de início, o ponto cego produzido pelo alcance diagnóstico que tem como horizonte um projeto inacabado de Modernidade. Em grande medida, para Habermas, a crise em nada está implicada no projeto de Modernidade, uma vez que envolveria fatores variados e independentes de uma narrativa única de filosofia da história. A Modernidade se apresenta como um horizonte normativo em aberto e as crises não resultam necessariamente desta trajetória histórico-normativa. Fica de fora a própria miséria estruturante dos processos

\begin{tabular}{|l|l|l|l|l|}
\hline Govista Qialectus & Ano 8 & n. 14 & Janeiro - Julho 2019 & p. 34 - 51 \\
\hline
\end{tabular}


modernos - o que aproxima Habermas mais do campo da Teoria Tradicional do que daquele próprio à Teoria Crítica.

Com efeito, este ponto cego acompanha o giro normativo que sustenta a defesa habermasiana de reforço das instituições liberal-democráticas contra potenciais pré-modernos que habitam as esferas político-econômicas. Nesse sentido, Habermas explicaria a tendência nazista assentar suas raízes no território alemão e não na França e na Inglaterra (onde uma estrutura moderna de Estado já havia avançado). Compreende assim a tese da Sonderweg: "a falha da classe média alemã" (representada pela sua social-democracia) em destruir as instituições feudais anacrônicas acabou por não estabelecer um Estado moderno com instituições políticas liberal-democráticas, como naqueles outros países europeus (ABROMEIT, 2017, p. 2). Em resposta a esse descompasso, Habermas defende o estabelecimento de um campo normativo para o equilíbrio institucional, como sua aposta pela Constituição da União Europeia (HABERMAS, 2001).

Diante desse lance, Abromeit traz uma questão de fundo: e se a própria ideia de uma normatividade não carrega consigo os efeitos da impotência desta perspectiva diante da ascensão de movimentos autoritários e populistas no coração das sociedades democráticas e modernas? Aqui, a suspeita converge com a análise de Amy Allen, para quem o ponto cego da perspectiva normativa se localiza na ideia de "progresso", que permanece intocada no projeto de Modernidade(s) que a segunda geração de Frankfurt ainda sustenta (ALLEN, 2016, p. 54). ${ }^{6}$ Em seu The end of progress: decolonizing the Normative foundations of Critical Theory, Allen destaca o vínculo entre a perspectiva normativa e uma ideia de progresso que avance sobre as manifestações pré-modernas, não modernas ou tradicionais. Assim, para a autora, as teorias críticas de Habermas e Honneth acabam comprometidas com a defesa de alguma ideia de progresso histórico "para fundamentar sua aproximação singular com a normatividade e, pois, para ser verdadeiramente crítico" (ALLEN, 2016, p. 21-22). No entanto, continua Allen em vistas dos processos modernos de colonização, "a linguagem do progresso e do desenvolvimento é a linguagem da opressão e da dominação para dois terços da população mundial" (ALLEN, 2016, p. 22). Nesse sentido, a perspectiva normativa exige uma crítica sobre

6 Considerando que o próprio Habermas, ao tratar o projeto de Modernidade como "inacabado", permite a revisão contínua deste conceito, de modo a defender em seus trabalhos mais recentes a ideia de múltiplas modernidades. Para Allen, no entanto, essa reformulação ainda é insuficiente: o modelo de progresso normativo persiste seja em uma única ou em múltiplas modernidades (ALLEN, 2016, p. 79-90).

\begin{tabular}{|c|c|c|c|c|}
\hline QRovista Dialectus & Ano 8 & n. 14 & Janeiro - Julho 2019 & p. $34-51$ \\
\hline
\end{tabular}


seus próprios pressupostos: uma crítica do progresso presente em autores da primeira geração de Frankfurt e deixada como ponto cego na teoria crítica normativa de Habermas e Honneth.

Ora, é esta perspectiva de progresso que, segundo Abromeit, torna insuficiente a perspectiva normativa mediante fenômenos contemporâneos do autoritarismo e do populismo conservadores. A suspeita pela insuficiência da normatividade é válida, neste contexto, que se desenrolava desde os anos 1970, quando o neoliberalismo ganha força e se torna um projeto político de desregulamentação da vida social em prol da mais bruta competição do livre mercado. Em contrapartida, esse mesmo movimento torna interessante os autores da primeira geração de Frankfurt, como Adorno, que em 1959 considerava "a sobrevivência do NacionalSocialismo na democracia potencialmente mais ameaçadora do que a sobrevivência de tendências fascistas contra a democracia" (ADORNO, 1995, p. 30). Talvez vivamos num período sui generis em que, dialeticamente, o autoritarismo contra a democracia sobreviva na democracia. De todo modo, esse movimento faz com que o retorno à primeira geração apresente um interesse peculiar para nosso tempo, recuperando o "estranhamento" da mensagem que Marcuse (mas também seus colegas de Frankfurt) escreveram na garrafa que encontramos agora: o que implica fazer uma crítica à democracia em vistas da democracia? Seria esse o ponto cego que a perspectiva normativa contém?

\section{Marcuse e a crítica à democracia}

Diante do mesmo impasse sobre o destino da normatividade na Teoria Crítica, Arnold Farr afirma que Marcuse representa um "ponto cego" na relação entre as teorias críticas das primeira e segunda gerações da Escola de Frankfurt. Afinal,

\footnotetext{
Diferentemente de Horkheimer e Adorno, a teoria crítica de Marcuse não nos conduz para a paralisia política da dominação total e da administração total. Diferentemente de Habermas, Marcuse não separa de maneira ingênua a esfera da racionalidade instrumental (sistema) da esfera da racionalidade comunicacional (mundo da vida). (FARR, 2013, p. 281).
}

Em consequência, prossegue Farr, está presente em Marcuse um projeto mais radical do que ambas as posições. Em seu juízo crítico que tensiona o valor a priori da vida digna e as potências a posteriori de transformação social, Marcuse "leva à sério" o papel da dominação e da racionalidade instrumental tanto no nível econômico-político quanto no nível

\begin{tabular}{|c|c|c|c|c|}
\hline Gevista Qialectus & Ano 8 & n. 14 & Janeiro - Julho 2019 & p. 34 - 51 \\
\hline
\end{tabular}


do mundo da vida (basta notar o caráter unidimensional presente tanto as relações sociais quanto o campo da linguagem e do pensamento do status quo). Além disso, seu diagnóstico de paralisia da crítica serve como advertência para uma nova orientação crítica em busca da subjetividade radical e transformadora, as potencialidades de transformação nas engrenagens unidimensionais - o que o afasta do diagnóstico de Adorno e Horkheimer. Deste ponto de vista, questionamos o enquadramento normativo que a segunda geração da Escola de Frankfurt procura delimitar o pensamento marcuseano. Seu "ponto cego" nessa narrativa talvez nos ofereça mais elementos, sobretudo em tempos que este referencial passa a ser questionado pelos novos desafios de um contexto social do populismo conservador.

Em seu ensaio "O destino histórico da democracia burguesa"7, Marcuse - que não retornou à Alemanha com o fim da II Guerra Mundial, permanecendo nos Estados Unidos - acompanha de perto as mazelas da democracia estadunidense e sua inversão para a política imperialista. Neste ensaio, Marcuse se questiona pelos motivos que fazem uma camada expressiva da população eleger um representante que alimenta a "cultura da morte". Ela não está manifesta nos discursos de Nixon, mas também nos noticiários diários de violência, das taxas de morte na Guerra do Vietnã, ou mesmo na defesa, como ultima ratio, da "solução final" (o extermínio dos inimigos) (MARCUSE, 2001, p. 172). A democracia burguesa que Marcuse passa a analisar, pois, não é efeito simplesmente de instituições pré-modernas que precisam ser reformuladas. Ao atravessar as mais diversas esferas sociais e institucionais, o que persiste é o fortalecimento de discursos da violência, expressões presentes nas opções pela morte dos discursos cotidianos propagados pela mídia, como a mãe de três estudantes do Estado do Kent, os quais estavam em protesto. Para ela, seus filhos deveriam ser "retirados à força" no caso de não obedecerem aos guardas (MARCUSE, 2001, p. 172). O exemplo é interessante pois mostra as interferências da cultura da violência entranhadas nas diversas instâncias sociais, incluindo aqui a relação (tão elementar para Honneth) entre a mãe e seus filhos.

De maneira muito similar aos pressupostos de uma perspectiva normativa, o empírico se apresenta nessa descrição de Marcuse aliado às possibilidades de transformação

7 O ensaio datado de 1972 não foi publicado por Marcuse. Trata de compreender como a população americana elegeu o discurso beligerante de Nixon a despeito de toda a mobilização contra o militarismo e o autoritarismo que o candidato representava. Os editores dos Collected Papers de Herbert Marcuse, que reúne diversos inéditos do autor, sugerem que o fato deste ensaio não ser publicado pode ser explicado pelo contexto histórico que segue à eleição de Nixon, o escândalo de Watergate, que levou ao processo de seu impeachment. Apesar de não ter publicado, insistimos que muitas das teses apresentadas então sustentam outros ensaios de grande relevância publicado pelo autor (em especial, Tolerância Repressiva) e que, em grande medida, explica suas análises publicadas sobre o caso Watergate.

\begin{tabular}{|l|l|l|l|l|}
\hline Gevista Qialectus & Ano 8 & n. 14 & Janeiro - Julho 2019 & p. $34-51$ \\
\hline
\end{tabular}


social (ou seus impedimentos). Nesta descrição, no entanto, algo escapa dos pressupostos normativos: há um bloqueio no reconhecimento intersubjetivo e, mais ainda, um reforço de instâncias próprias à cultura da violência, do medo e da morte - o que Marcuse pretende descrever como uma cultura "sadomasoquista" presente nas instâncias da democracia burguesa. Remete aqui ao território de ambiguidades tão bem explorado pelo Marquês de Sade, para quem, desde as raízes históricas da democracia burguesa e seu regime de contratos, "crueldade, injustiça e vício são recompensadas invariavelmente, enquanto virtude, moralidade, justiça são invariavelmente punidas" (MARCUSE, 2001, p. 173). Com isso, nosso autor não se resigna a descrever a democracia como um sistema imperfeito de vícios, mas procura entender nas raízes morais de sua crítica as possibilidades políticas que tanto sustentam o status quo quanto rendem as revoltas para transcende-lo.

Não é o fiel da balança normativa que vai orientar a compreensão de Marcuse sobre o fenômeno do neofascismo. Sobretudo, em uma condição social que perde o caráter objetivo que sustentaria uma perspectiva normativa da Teoria Crítica. Diante de uma justiça sadomasoquista, o espelhamento entre o justo e o injusto, entre o respeito e o desrespeito deixa de ser a medida que fornece diagnósticos. Vejam os casos da "função ambivalente dos direitos civis": embora eles tenham de ser defendidos por todos os meios, Marcuse também nota como estes direitos têm servido aos governos proto-fascistas que os controlam de maneira cada vez mais aberta. Manifestação de violências e ameaças aos grupos sociais surgem como manifestações da liberdade de expressão. Segundo nosso autor: a "noção de objetividade, tão central às operações da sociedade civilizada, tem sido invalidada (mais ainda, tornada em seu oposto)" pelo próprio governo. Na dissolução objetiva que orienta a opinião, o que acaba se promovendo é "agressividade, opressão, crime" de modo a tornar público as "mais ultrajantes exortações à violência - a violência sadomasoquista arraigada no Establishment" (MARCUSE, 2001, p. 177).

Não seria justamente esta objetividade a matriz para uma perspectiva normativa da Teoria Crítica? Ou seja, para contrariar a dissimulação da objetividade pelo autoritarismo presente em vias da democracia burguesa, a melhor resposta não seria a defesa de critérios normativos constituídos histórico-materialmente pela gramática dos conflitos sociais? Esta poderia ser uma questão trazida pela reflexão honnethiana. Mas, ao analisar a resposta de Marcuse ao problema da dissimulação da objetividade pelo autoritarismo em vias democráticoburguesas, percebemos que o campo normativo é insuficiente. Subverter esta ideologia

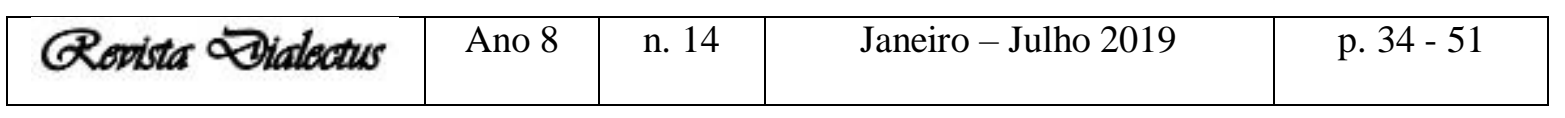


sadomasoquista exige forças mais poderosas do que o esclarecimento normativo. Essa estratégia encurrala a própria Esquerda que segue em defesa da democracia como um "mal menor", reduzindo cada vez mais as possibilidades de emancipação ao território democrático do status quo (MARCUSE, 2001, p. 177). De outro modo, é preciso enfrentar o afeto social central na cultura sadomasoquista: é preciso conquistar o medo (MARCUSE, 2001, p. 173) que está manifesta na dor, no sofrimento e na perda manifestas quando o status quo é ameaçado.

Decerto, a abertura crítica que Marcuse opera procura se afastar da grade normativa que lhe renderia a insuficiente proposição de reformas institucionais. Elemento evidentemente insuficiente em um contexto histórico em que a democracia burguesa encontra suas vias autoritárias, sobretudo, com a dissolução de limites institucionais, com o “desaparecimento da distinção entre negócios, máfia e política", fazendo da "corrupção" um termo sem a menor significação política (MARCUSE, 2001, p. 176) e abrindo espaço, como vimos, para o campo aberto das violências sadomasoquistas. No entanto, isso não significa que Marcuse abandone elementos centrais para a formulação da experiência política. De outro modo, minimizar as questões morais é um erro político. Pois, no campo moral está implicada a possibilidade de, ao mesmo tempo, utilizar as instituições democráticas enquanto combate as forças que, na democracia, fazem das pessoas os arautos das tendências conservadoras, reacionárias e mesmo neofascistas (MARCUSE, 2001, p. 178). Isto é, será pelo reconhecimento dos "conteúdos materiais das questões morais" (anterior ao caráter formal e normativo das injustiças) que a cultura sadomasoquista pode ser enfrentada (MARCUSE, 2001, p. 179).

\section{Conclusão: Decifrando a mensagem, hoje.}

Mas o que seria tal "conteúdo material"? De imediato, Marcuse apresenta a materialidade da moral como "a substância e o potencial políticos" contidos na questão moral (MARCUSE, 2001, p. 179). Aos poucos, ele procura trazer uma melhor compreensão mediante os exemplos em que o campo moral exerce papel central nas lutas sociais. A solidariedade, por si só, seria uma palavra isolada e até um bom valor de mercado em tempos como o nosso, em que corporações acabam fazendo da vulnerabilidade social um grande motivo de investimento de capitais. No entanto, seu conteúdo político é recuperado junto às significativas lutas sociais: não apenas quando os grupos sociais se manifestam em massa e contribuem entre si por suas causas, mas também quando a solidariedade rompe a identificação da classe trabalhadora (bem como os movimentos estudantil, negro, feminista, indígenas etc.) com os interesses da classe

\begin{tabular}{|c|c|c|c|c|}
\hline Gevista Dialectus & Ano 8 & n. 14 & Janeiro - Julho 2019 & p. $34-51$ \\
\hline
\end{tabular}


dominante (MARCUSE, 2001, p. 179), e promovem, assim, camadas "sub-revolucionárias" presentes em todo processo revolucionário (MARCUSE, 2001, p. 182).

Talvez, na descrição que Marcuse faz a seus estudantes em Berkeley sobre os dias do Maio francês, notaremos um exercício crítico potente. Sua narrativa não era um enquadramento do movimento estudantil aos paradigmas teóricos de Eros e civilização. Em busca do conteúdo material e político dessa luta, Marcuse parte da descrição de como as vozes e os corpos passam a ocupar os espaços nas ruas de Paris e Nantèrre. A solidariedade destes corpos deixa de ser uma ideia. Há nesse embate um conteúdo material que se expressa como um modo de viver. Nesse sentido, descreve Marcuse:

chegou o tempo em que centenas de milhares e, como vemos agora, milhões de pessoas não queriam continuar fazendo a mesma coisa nunca mais: não queriam levantar de manhã e ir para o emprego e passar pela mesma rotina e escutar as mesmas ordens e concordar com as mesmas condições de trabalho e ter os mesmos desempenhos. Eles simplesmente se recusaram a fazer. Alguns ficaram em suas casas, outros saíram para passear e outros tentaram fazer algo (MARCUSE, 2005, p. 45).

Tal descrição de indeterminações está longe de ser o retrato de um progresso normativo. Uma filosofia que pensa a partir da espontaneidade dos movimentos sociais voltase para a ordenação material de suas relações e valores. Não à toa, em sua descrição do Maio Francês, Marcuse assinala as relações entre corpos: primeiro estudantes, depois a adesão de trabalhadores e trabalhadoras ao movimento. Decerto, este não é um encadeamento lógico dos fatos. Existem contradições em meio aos corpos estudantis e laborais, presentes mesmo quando enfrentam em conjunto o Establishment. Mas, talvez, é este encontro de contradições que torna potente um movimento como esse, para Marcuse. O campo moral não se neutraliza, mas se evidencia em seu conteúdo material e político dos corpos em luta.

Em seu livro mais recente sobre as políticas nas ruas, Judith Butler sugere algo semelhante ao que está em jogo na descrição de Marcuse. Segundo a autora:

a política não se define por tomar lugar exclusivamente na esfera pública, distinta da esfera privada, mas atravessa essas linhas repetidas vezes, chamando atenção para a maneira como a política já está nas casas, nas ruas, na vizinhança ou, de fato, nos espaços virtuais que estão igualmente livres da arquitetura da casa e da praça (BUTLER, 2018, p. 80-81).

\begin{tabular}{|c|c|c|c|c|}
\hline Rovista Dialectus & Ano 8 & n. 14 & Janeiro - Julho 2019 & p. $34-51$ \\
\hline
\end{tabular}


Butler nota que a política não é, de imediato, um espaço normativo, mas um exercício diverso que leva em consideração a organização material dos espaços. Não existe política sem corpos (mesmo quando desaparecidos, eles têm voz). Creio que tal presença dos corpos é o que está na descrição de Marcuse sobre o Maio Francês. Sua Teoria Crítica rompe os quadros normativos e nisso opera um ponto cego: pois o que está em questão não é o diagnóstico da Modernidade, mas a necessidade provocada pelo contorno dos acontecimentos e dos corpos. Escutar os corpos em sua revolta: por isso, Marcuse vai mais além da normatividade. Em contrapartida, exige uma teoria crítica orientada pela ordem material dos acontecimentos. Assim, não é o progresso normativo que identifica o pensamento crítico marcuseano, mas o conteúdo material da moral: sua substância e potencialidade políticas presentes nos corpos e nos acontecimentos.

\section{Referências:}

ABROMEIT, J. Right-wing populism and the limits of normative critical theory. In: Logos: a journal of modern society and culture, vol. 16, $\mathrm{n}^{\circ}$ 1-2, 2017, http://logosjournal.com/2017/rightwing-populism-and-the-limits-of-normative-criticaltheory/ (acessado em 15/12/2018).

ADORNO, T. W. "O que significa elaborar o passado". In: ADORNO, T. W. Educação e emancipação. Tradução de Wolfgang Leo Maar, Rio de Janeiro: Paz e Terra, 1995.

ALLEN, A. The end of progress: decolonizing the normative foundations of critical theory. New York: Columbia University Press, 2016.

BENHABIB, S. Critique, norm, and utopia: a study on the Foundations of Critical Theory. New York: Columbia University Press, 1986.

BUTLER, J. Corpos em aliança e a política das ruas: Notas para uma teoria performativa de assembleia, tradução de Fernanda S. Miguens, Rio de Janeiro: Civilização Brasileira, 2018.

CARNEIRO, S. A paralisia da crítica e a democracia como tabu. In: Revista Fevereiro, vol. 7 , http://www.revistafevereiro.com/pag.php?r=07\&t=08 (acessada em 15/12/2018).

FARR, A. In search of radical subjectivity: rereading Marcuse after Honneth. In: Radical philosophy review, vol. 16, $\mathrm{n}^{\circ} 1,2013$.

FORST, R. Justificação e crítica: perspectiva de uma teoria crítica da política. Tradução de Denilson L. Werle, São Paulo: Ed. UNESP, 2018.

\begin{tabular}{|l|c|c|c|c|}
\cline { 2 - 4 } Govista & Ano 8 & n. 14 & Janeiro - Julho 2019 & p. 34 - 51 \\
\hline
\end{tabular}


FRASER, N e HONNETH, A. Redistribution or recognition? A political-philosophical exchange, translated by Joel Golb et al., London, New York; Verso, 2004.

HABERMAS, J. O discurso filosófico da modernidade: doze lições. Tradução de Luiz Reppa et al. São Paulo: Martins Fontes, 2000.

. Why Europe needs a constitution? In: New left review, vol. 11, sept-oct 2001, https://newleftreview.org/II/11/jurgen-habermas-why-europe-needs-a-constitution (acessado em 15/12/2018).

HONNETH, A. Teoria crítica. In: GIDDENS, A et al. (org.). Teoria social hoje. Tradução de Gilson C. C. de Souza, São Paulo, Ed. UNESP, 1999, p. 503-552.

Luta por reconhecimento: a gramática moral dos conflitos sociais, tradução de Luiz Repa, São Paulo: Ed. 34, 2003. Press, 2007.

Disrespect: the normative foundations of critical theory. Cambridge, Malden: Polity

HORKHEIMER, M. Teoria tradicional e teoria crítica. In: BENJAMIN, W. et al. Os pensadores, traduções de José L. Grünnewald et al. São Paulo: Ed. Abril Cultural, 1983, p. 117-154.

MARCUSE, H. Eros and civilization: a philosophical inquiry into Freud. Boston: Beacon Press, 1966.

. Soviet marxism: a critical analysis. New York: Columbia University Press, 1985.

One-dimensional man: studies in the ideology of advanced industrial societies.

London: New York: Routledge, 1991.

Filosofia e teoria crítica. In: MARCUSE, H., Cultura e sociedade. Traduções de Wolfgang L. Maar et al. Volume 1. São Paulo: Paz e Terra, 1997, p. 137-160.

. The historical fate of bourgeois democracy. In: MARCUSE, H. Towards a critical theory of society - collected papers of Herbert Marcuse. Volume 2. London, New York: Routledge, 2001, p. 163-186.

Reflections on French revolution. In: MARCUSE, H. The new left and the 1960s collected papers of Herbert Marcuse. Volume 3. London, New York: Routledge, 2005, p. 40-45.

\begin{tabular}{|c|c|c|c|c|}
\hline QRovista Dialectus & Ano 8 & n. 12 & Janeiro - Julho 2019 & p. $34-51$ \\
\hline
\end{tabular}

